\title{
Hemothorax by Intercostal Varicose Veins in Alcoholic Liver Cirrhosis
}

\author{
Gian Luca Casoni ${ }^{a}$ Carlo Gurioli ${ }^{a}$ Ruggero Corso ${ }^{b}$ Christian Gurioli ${ }^{a}$ \\ Venerino Poletti ${ }^{\mathrm{a}}$ \\ a Dipartimento Toracico and b Dipartimento di Emergenza, Ospedale G.B. Morgagni, Forlì, Italy
}

A 58-year-old man with alcoholic liver cirrhosis and signs related to portal hypertension (such as esophageal varices) was admitted to the GB Morgagni hospital (Forli, Italy) because of acute-onset breathlessness and weakness. His blood pressure was $90 / 55$ and laboratory values showed anemia (hemoglobin $7.9 \mathrm{~g} / \mathrm{dl}$, hematocrit 23.5\%). Packed red cells ( 2 units) were immediately administered intravenously, after which the blood pressure rose to 110/65. Meanwhile, a posterioanterior chest radiograph demonstrated a massive right pleural effusion. A thoracentesis was performed and approximately $700 \mathrm{ml}$ of hemorrhagic pleural effusion was evacuated. The day after the thoracentesis the patient underwent medical thoracoscopy for evacuation of the pleural effusion and for diagnosis. After aspiration of 2,200 $\mathrm{ml}$ of hemorrhagic pleural fluid (with hematocrit of $8 \%$ ), the exploration of the thoracic cavity revealed at the 9 th and 10 th posterior intercostal space the presence of intercostal varicose veins with recent signs of bleeding (fig. 1a, b). A chest tube was placed. Twenty minutes after placement of the chest tube, the patient became more breathless and examination re-

Fig. 1. Thoracoscopic findings of intercostal varicose veins with recent signs of bleeding.

Fig. 2. Chest radiography repeated 20 minutes after the placement of a chest tube, showed a fully expanded right lung, albeit with features of pulmonary edema (probably ex vacuo) and substantial subcutaneous emphysema in the chest tube insertion.
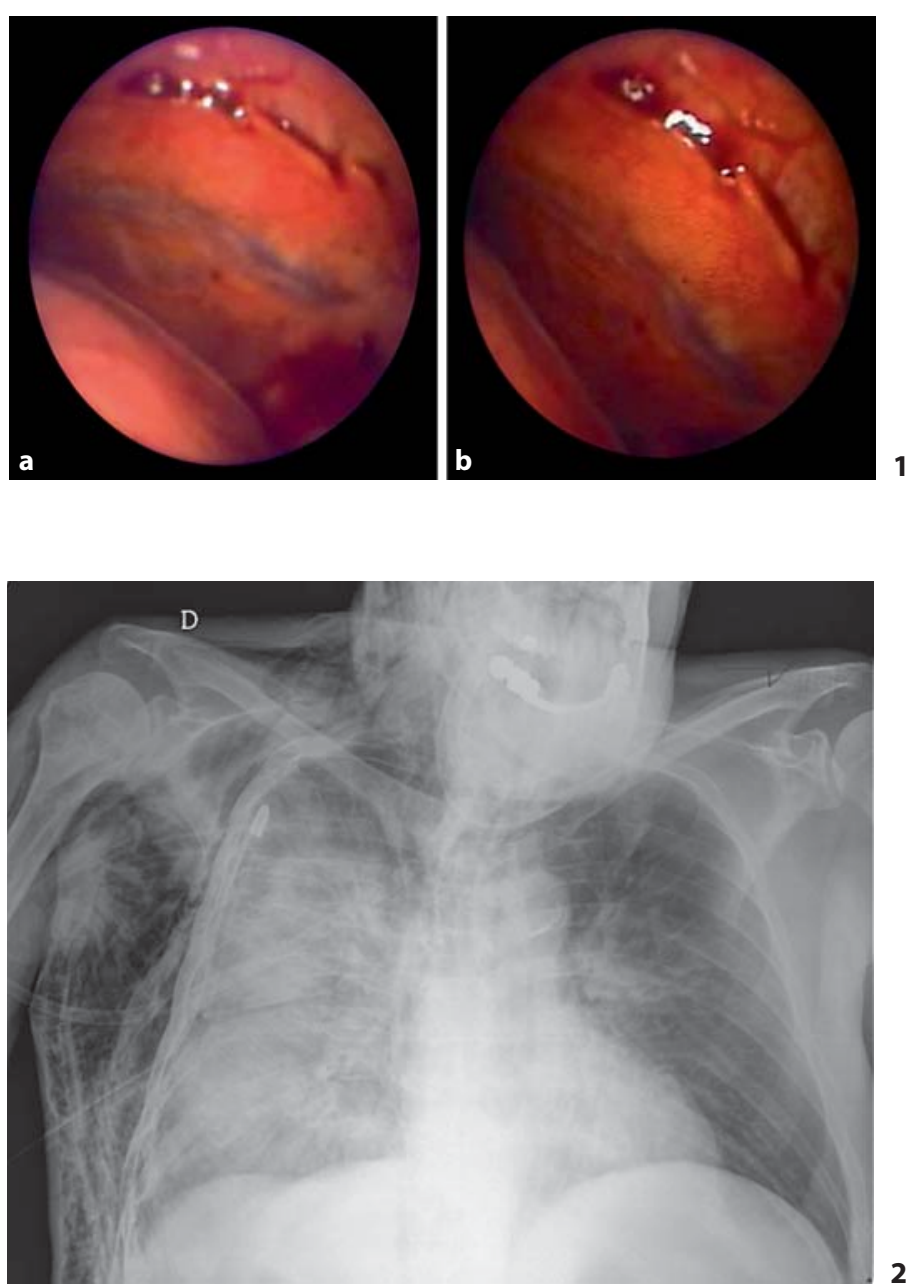
vealed extensive right-sided chest crackles. Chest radiography was repeated and showed a fully expanded right lung, albeit with features of pulmonary edema (probably ex vacuo; fig. 2). The patient died after 8 hours despite receiving the best supportive care.

Cirrhotic patients may acquire pulmonary or pleural complications that can be unrelated (e.g. tumors, pneumothorax, hemothorax) or directly related to portal hypertension (e.g. hepatic hydrothorax, spontaneous bacterial empyema, hepatopulmonary syndrome) $[1,2]$.

The mortality rate is high in these patients and, as expected, increases in the setting of more advanced liver dysfunction.

Complications of chest tube placement (in particular if prolonged) contribute significantly to mortality; hence, this procedure should be avoided whenever possible, especially in patients with advanced degrees of liver dysfunction [3].
1 Milanez de Campos JR, Filho LOA, de Campos Werebe E, et al: Thoracoscopy and talc poudrage in the management of hepatic hydrothorax. Chest 2000;118:13-17.

-2 Conklin LD, Estrera AL, Weiner MA, et al: Transjugular intrahepatic portosystemic shunt for recurrent hepatic hydrothorax. Ann Thorac Surg 2000;69:609-611.

-3 Liu LU, Haddadin HA, Bodian CA, Sigal SH, Korman JD, Bodenheimer HC Jr, Schiano TD: Outcome analysis of cirrhotic patients undergoing chest tube placement. Chest $2004 ; 126: 142-148$ 